\title{
Vector-Proportional-Integral Control of Inductor-Capacitor-Inductor Active Power Filter under the Alpha-Beta Stationary Coordinate System
}

\author{
Dandan Liu ${ }^{*}$, Lin Zhou ${ }^{2}$, Xiangyu Sai ${ }^{2}$ \\ ${ }^{1}$ College of Electronic Engineering, Yancheng Institute of Technology, Yancheng 224501, China \\ ${ }^{2}$ School of Electrical Engineering and Automation, Harbin Institute of Technology, Harbin 150001, China
}

Corresponding Author Email: 1dd@ycit.edu.cn

https://doi.org/10.18280/ejee.220110

Received: 10 August 2019

Accepted: 27 November 2019

\section{Keywords:}

Inductor-capacitor-inductor (LCL) filter, active power filter (APF), compensation for nth order harmonic current, alpha-beta $(\alpha-\beta)$ stationary coordinate system, vectorproportional-integral (VPI) current control

\begin{abstract}
The proportional-resonant (PR) controller is a traditional tool for current control. Due to the phase jump at the resonance point, the PR controller cannot compensate for the current in the inductor-capacitor-inductor (LCL)-based active power filter (APF) in a precise manner. To solve the problem, this paper puts forward a vector-proportional-integral (VPI) current control strategy, which relies on the VPI controller to compensate for the harmonic current of the $n$-th order under the alpha-beta $(\alpha-\beta)$ stationary coordinate system. Through theoretical analysis and contrastive experiment, it is learned that the closed-loop transfer function of the VPI controller satisfies $0 \mathrm{~dB}$ of amplitude-frequency at the resonance point, and controls the phase response at the resonance frequency at $0^{\circ}$. Hence, the VPI strategy can track the harmonic current with no error, and thus fully compensate for the harmonic current. The proposed control strategy improves the current compensation precision of APFs, and provides a reference for enhancing the power quality of the grid.
\end{abstract}

\section{INTRODUCTION}

Nonlinear loads like the power electronic equipment inject lots of harmonics and reactive power into the power system, reducing the power quality of the grid [1-4]. The injected harmonics can be compensated for with active power filters (APFs) in a precise, rapid and stable manner $[5,6]$. As a result, these filters have been widely adopted in various industrial sites [7-10]. Before injecting the harmonic compensation current to the load side, the AFPs must be connected to the grid [11]. Among the various AFPs, the inductor-capacitor-inductor (LCL) filter stands out in that it can achieve the same filtering effect with lower inductance, size and cost. Hence, the LCLAFP is more popular than any other type of AFPs $[12,13]$.

Current control, as the key to the APF design, directly bears on the precision of current compensation [14]. Traditionally, the APFs adopt the proportional-resonant (PR) strategy for current control. Under this strategy, phase jump may occur at the resonance point, making the compensation imprecise. To solve the problem, Kouadria et al. [15] put forward a hybrid fuzzy sliding-mode control strategy. Krama et al. [16] tuned APF offline through particle swarm optimization (PSO). Fang et al. [17] and Ullah et al. [18] tracked the ideal current with an adaptive fuzzy-neural fractional-order controller. Despite their theoretical significance, the above methods are difficult to implement in engineering, due to the complexity of parameter design. Mahela and Shaik [19] and Benaissa et al. [20] determined harmonic components directly by identifying harmonic current. This direct method is not highly applicable, owing to its heavy computing load. To overcome these defects, this paper puts forward a vector-proportional-integral (VPI) current control strategy to compensate the n-th order harmonic current under the alpha-beta $(\alpha-\beta)$ stationary coordinate system. The $\alpha-\beta$ stationary coordinate system was selected to simplify the coordinate transform in the control system and ease the computing load. Compared with those under the a-bc stationary coordinate system and the rotating coordinate system, the three phases of the current under the $\alpha-\beta$ stationary coordinate system are not coupled [21]. Thus, the disturbance of the grid voltage on the control system can be neglected. The proposed control strategy enhances the precision of the LCLAPF in harmonic current compensation.

This paper firstly constructs a mathematical model of the LCL-APF under the $\alpha-\beta$ stationary coordinate system, and then explains the principle of VPI current control under that system. Next, the VPI strategy was compared with the PR strategy under the $\alpha-\beta$ stationary coordinate system. Based on the digital signal processor (DSP), the hardware and software of the proposed control strategy were designed, creating an experimental platform for LCL-APFs. Finally, the superiority of our strategy over the PR strategy under the $\alpha-\beta$ stationary coordinate system was verified through experiments.

\section{MATHEMATICAL MODELLING}

The main circuit of the LCL-APF is shown in Figure 1 [2223], where $u_{s a}, u_{s b}$ and $u_{s c}$ are grid voltage, $i_{1 x}(x=a, b, c)$ is the converter-side current, $L_{l}$ is the converter-side inductance, $R_{1}$ is the parasitic resistance of converter-side inductor, $i_{2 x}(x=a, b$, $c$ ) is the grid-side current; $L_{2}$ is the grid-side inductance; is the parasitic resistance of grid-side inductor, and $C_{g}$ is the parallel capacitor. The voltage of the parallel capacitor and that of the direct current (DC)-side are denoted as $U_{g x}(x=a, b, c)$ and $U_{d c}$, respectively. As shown in Figure 1, the bridge arm of each phase consists of four power electronic switches, and each phase is connected in reverse parallel with two clamping diodes to clamp the bridge arm at the midpoint. 


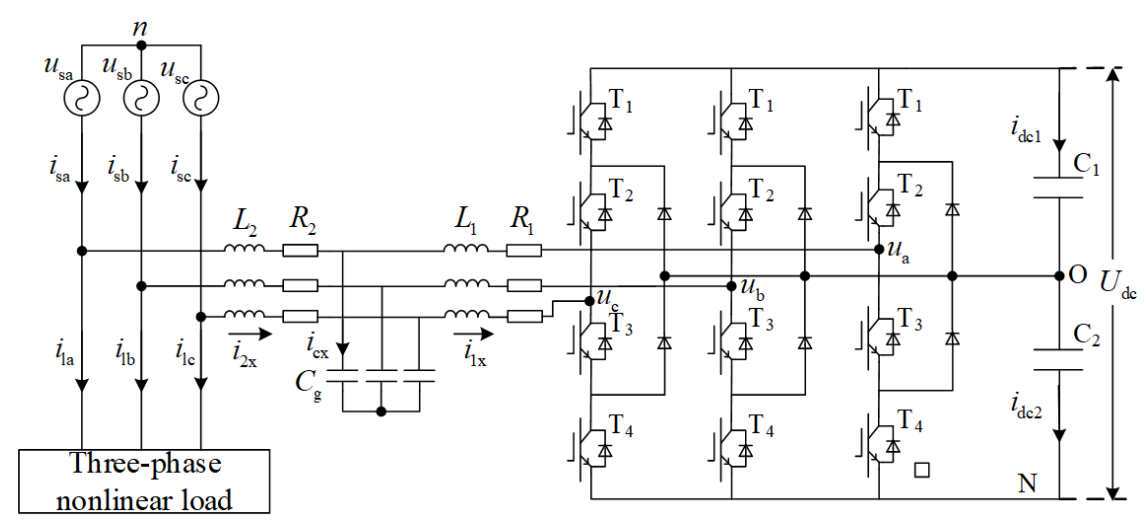

Figure 1. The main circuit of the LCL-APF

It is assumed that the power electronic switches on the main circuit of the LCL-APF take a negligible amount of time in phase change; the inductors are selected correctly to prevent saturation under normal working conditions; the three phases are balanced in the grid-side system. Under these assumptions, the mathematical model of the LCL-APF was established based on the switching function.

On the main circuit of the LCL-APF, the on-off states of the three bridge arms in the three-phase converter can be denoted as switching variables $S_{a}, S_{b}$ and $S_{c}$, respectively. Take the phase a bridge arm for example. This bridge arm has four power electronic switches, and thus three on-off states. The switching function $S_{a}$ of the bridge arm can be expressed as:

$$
S_{\mathrm{a}}= \begin{cases}1 & \left(T_{1} \text { and } T_{2} \text { are on; } T_{3} \text { and } T_{4} \text { are off }\right) \\ 0 & \left(T_{2} \text { and } T_{3} \text { are on } ; T_{1} \text { and } T_{4} \text { are off }\right) \\ -1 & \left(T_{3} \text { and } T_{4} \text { are on } ; T_{1} \text { and } T_{2} \text { are off }\right)\end{cases}
$$

As shown in formula (1), under state 1 , switches $T_{1}$ and $T_{2}$ are on, while switches $\mathrm{T}_{3}$ and $\mathrm{T}_{4}$ are off; under state 0 , switches $T_{2}$ and $T_{3}$ are on, while switches $T_{1}$ and $T_{4}$ are off; under state -1 , switches $T_{3}$ and $T_{4}$ are on, while switches $T_{1}$ and $T_{2}$ are off.

For convenience, the switching function was further decomposed as follows [24]: if $S_{a}=1$, then $S_{1 a}=1, S_{2 a}=0$ and $S_{3 a}=0$; if $S_{a}=0$, then $S_{1 a}=1, S_{2 a}=0$ and $S_{3 a}=1$; if $S_{a}=-1$, then $S_{1 a}=1$, $S_{2 a}=1$ and $S_{3 a}=0$. The switching functions of phase b and phase c were defined and decomposed as that of phase a.

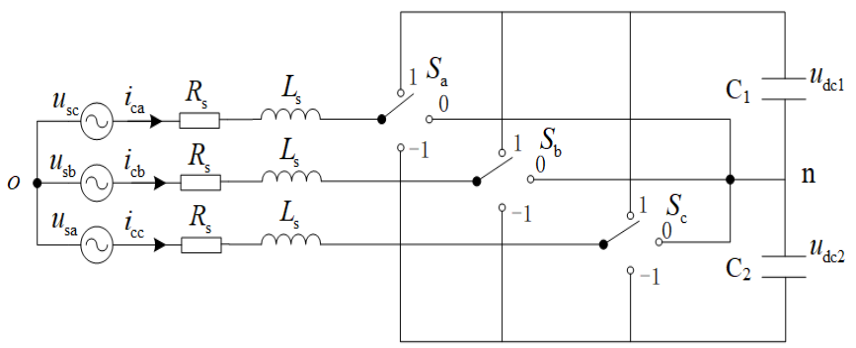

Figure 2. The equivalent circuit of the LCL-APF

If the frequency band is effectively controlled, the LCL filter is equivalent to an inductor (L) filter [25]. Hence, the parallel capacitance was neglected, and the parasitic resistances of grid-side and converter-side inductors in the LCL-APF were converted into an equivalent resistance $R_{\mathrm{s}}$, and the grid-side and converter-side inductances were converted into an equivalent inductance $L_{\mathrm{s}}$. In this way, the equivalent circuit of the LCL-APF can be obtained as Figure 2 above.

According to the equivalent circuit and Kirchhoff's voltage law (KVL), the three-phase voltage loop can be described as:

$$
\left.\begin{array}{c}
L_{s} \frac{d i_{c a}}{d t}=u_{s a}-R_{s} i_{c a}-u_{a n}-u_{n o}, \\
L_{s} \frac{d i_{c b}}{d t}=u_{s b}-R_{s} i_{c b}-u_{b n}-u_{n o}, \\
L_{s} \frac{d i_{c c}}{d t}=u_{s c}-R_{s} i_{c c}-u_{c n}-u_{n o} \circ
\end{array}\right\}
$$

where, $u_{s x}(x=a, b, c)$ is the three-phase grid voltage $(\mathrm{V}) ; i_{c x}(x=a$, $b, c)$ is the three-phase compensation current of the LCL-APF (A); $u_{x n}(x=a, b, c)$ is the output voltage of the converter $(\mathrm{V}) ; L_{s}$ is the equivalent inductance of the LCL-APF $(\mathrm{mH}) ; R_{s}$ is the equivalent resistance of the LCL-APF $(\Omega) ; u_{n o}$ is the neutralpoint potential difference between the converter-side and the grid-side (V);

$$
\begin{gathered}
u_{j n}=S_{1 j} u_{\mathrm{dc} 1}+S_{3 j} u_{\mathrm{dc} 2}(j=\mathrm{a}, \mathrm{b}, c) \\
u_{n o}=-\left(u_{a n}+u_{b n}+u_{c n}\right) / 3
\end{gathered}
$$

Next, the three-phase current loop can be described by the Kirchhoff's current law (KCL) as:

$$
\left.\begin{array}{l}
C_{1} \frac{d u_{\mathrm{dc} 1}}{d t}=S_{1 \mathrm{a}} i_{c \mathrm{a}}+S_{1 b} i_{c b}+S_{1 c} i_{c c} \\
C 2 \frac{d u_{\mathrm{dc} 2}}{d t}=S_{2 \mathrm{a}} i_{c \mathrm{a}}+S_{2 b} i_{c b}+S_{2 c} i_{c c}
\end{array}\right\}
$$

Then, the mathematical model of the LCL-APF under the abc stationary coordinate system can be derived from formula (2) and formula (5):

$$
\begin{gathered}
\boldsymbol{Z} \dot{\boldsymbol{X}}=\boldsymbol{A} \boldsymbol{X}+\boldsymbol{B} \boldsymbol{e} \\
\boldsymbol{Z}=\operatorname{diag}\left[\begin{array}{lllll}
L_{s} & L_{s} & L_{s} & \mathrm{C}_{1} & \mathrm{C}_{2}
\end{array}\right] \\
\boldsymbol{X}=\left[\begin{array}{lllll}
i_{c \mathrm{a}} & i_{c b} & i_{c c} & u_{\mathrm{dc} 1} & u_{\mathrm{dc} 2}
\end{array}\right]^{T}
\end{gathered}
$$




$$
A=\left[\begin{array}{ccccc}
-R_{s} & 0 & 0 & -\mathrm{S}_{1 \mathrm{a}}+\frac{S_{1 \mathrm{a}}+S_{1 b}+S_{1 c}}{3} & \mathrm{~S}_{2 \mathrm{a}}-\frac{S_{2 \mathrm{a}}+S_{2 b}+S_{2 c}}{3} \\
0 & -\mathrm{R}_{\mathrm{s}} & 0 & -\mathrm{S}_{1 b}+\frac{S_{1 \mathrm{a}}+S_{1 b}+S_{1 c}}{3} & \mathrm{~S}_{2 \mathrm{~b}}-\frac{S_{2 \mathrm{a}}+S_{2 b}+S_{2 c}}{3} \\
0 & 0 & -\mathrm{R}_{\mathrm{s}} & -\mathrm{S}_{1 c}+\frac{S_{1 \mathrm{a}}+S_{1 b}+S_{1 c}}{3} & \mathrm{~S}_{2 \mathrm{c}}-\frac{S_{2 \mathrm{a}}+S_{2 b}+S_{2 c}}{3} \\
S_{1 \mathrm{a}} & S_{1 b} & S_{1 c} & 0 & 0 \\
-S_{2 \mathrm{a}}-S_{2 \mathrm{~b}}-S_{2 c} & 0 & 0
\end{array}\right]
$$

$$
\begin{gathered}
\boldsymbol{B}=\operatorname{diag}\left[\begin{array}{lllll}
1 & 1 & 1 & 0 & 0
\end{array}\right] \\
\boldsymbol{e}=\left[\begin{array}{lllll}
u_{\mathrm{sa}} & u_{\mathrm{sb}} & u_{\mathrm{sc}} & 0 & 0
\end{array}\right]^{T}
\end{gathered}
$$

The abc stationary coordinate system was converted into the $\alpha-\beta$ stationary coordinate system by the equal power transform matrix $\boldsymbol{C}_{3 s / 2 s}$ :

$$
\boldsymbol{C}_{3 s / 2 s}=\sqrt{\frac{2}{3}}\left[\begin{array}{ccc}
1 & -\frac{1}{2} & -\frac{1}{2} \\
0 & \frac{\sqrt{3}}{2} & -\frac{\sqrt{3}}{2}
\end{array}\right]
$$

Through the transform, the grid voltage $u_{s}$, LCL-APF output current $i_{c}$ and LCL-APF switching function $S$ can be described as follows under the $\alpha-\beta$ stationary coordinate system:

$$
\left.\left.\begin{array}{l}
u_{s}=u_{\alpha}+j u_{\beta}=\sqrt{\frac{2}{3}}\left[\left(u_{s \mathrm{a}}-\frac{1}{2} u_{s b}-\frac{1}{2} u_{s c}\right)+j\left(\sqrt{\frac{3}{2}} u_{s b}-\sqrt{\frac{3}{2}} u_{s c}\right)\right], \\
i_{c}=i_{c \alpha}+j i_{c \beta}=\sqrt{\frac{2}{3}}\left[\left(i_{\mathrm{ca}}-\frac{1}{2} i_{c b}-\frac{1}{2} i_{c c}\right)+j\left(\sqrt{\frac{3}{2}} i_{c b}-\sqrt{\frac{3}{2}} i_{c c}\right)\right] \\
S_{\alpha 1}+j S_{\beta 1}=\sqrt{\frac{2}{3}}\left[\left(S_{\mathrm{a} 1}-\frac{1}{2} S_{b 1}-\frac{1}{2} S_{c 1}\right)+j\left(\sqrt{\frac{3}{2}} S_{b 1}-\sqrt{\frac{3}{2}} S_{c 1}\right)\right], \\
S_{\alpha 2}+j S_{\beta 2}=\sqrt{\frac{2}{3}}\left[\left(S_{\mathrm{a} 2}-\frac{1}{2} S_{b 2}-\frac{1}{2} S_{c 2}\right)+j\left(\sqrt{\frac{3}{2}} S_{b 2}-\sqrt{\frac{3}{2}} S_{c 2}\right)\right]
\end{array}\right\}\right\}
$$

To sum up, the mathematical model of the LCL-APF under the $\alpha-\beta$ stationary coordinate system can be established as:

$$
Z \dot{X}=A X+B e
$$

$$
\begin{gathered}
\boldsymbol{Z}=\operatorname{diag}\left[\begin{array}{llll}
L_{s} & L_{s} & \mathrm{C}_{1} & \mathrm{C}_{2}
\end{array}\right] \\
\boldsymbol{X}=\left[\begin{array}{lllll}
i_{\alpha} & i_{\beta} & u_{\mathrm{cd} 1} & u_{\mathrm{cd} 2}
\end{array}\right]^{T} \\
\boldsymbol{B}=\operatorname{diag}\left[\begin{array}{lllll}
1 & 1 & 1 & 0 & 0
\end{array}\right] \\
\boldsymbol{e}=\left[\begin{array}{llll}
u_{\alpha} & u_{\beta} & 0 & 0
\end{array}\right]^{T} \\
A=\left[\begin{array}{ccccc}
-R_{s} & 0 & -\mathrm{S}_{\alpha 1} & \mathrm{~S}_{\alpha 2} \\
0 & -\mathrm{R}_{\mathrm{s}} & -\mathrm{S}_{\beta 1} & \mathrm{~S}_{\beta 2} \\
S_{\alpha 1} & S_{\beta 1} & 0 & 0 \\
-S_{\alpha 2} & -S_{\beta 2} & 0 & 0
\end{array}\right]
\end{gathered}
$$

It can be seen that the mathematical model of the LCL-APF has no coupling between variables on the two axes under the $\alpha-\beta$ stationary coordinate system. The two phases are independent of each other. Thus, each axis can be studied as a single phase system.

\section{PRINCIPLE OF OUR CURRENT CONTROL STRATEGY UNDER A-B STATIONARY COORDINATE SYSTEM}

The framework of VPI current control under the $\alpha-\beta$ stationary coordinate system was analyzed in details to verify the feasibility of the strategy. Figure 3 illustrates the principle of the VPI current control under the said system.

In Figure 3, the harmonic current is detected in the following steps: first, the three-phase currents of the nonlinear load and the grid are sampled; the harmonic compensation command is computed and converted through Clarke transform into the APF current command under the $\alpha-\beta$ stationary coordinate system; then, the current command is imported to the VPI current controller; after that, the output of the controller is taken as the sinusoidal pulse width modulation (SPWM) voltage command, and inputted to the SPWM device; finally, the pulse width modulation (PWM) signal is sent to the APF converter to complete the closed-loop control of current.

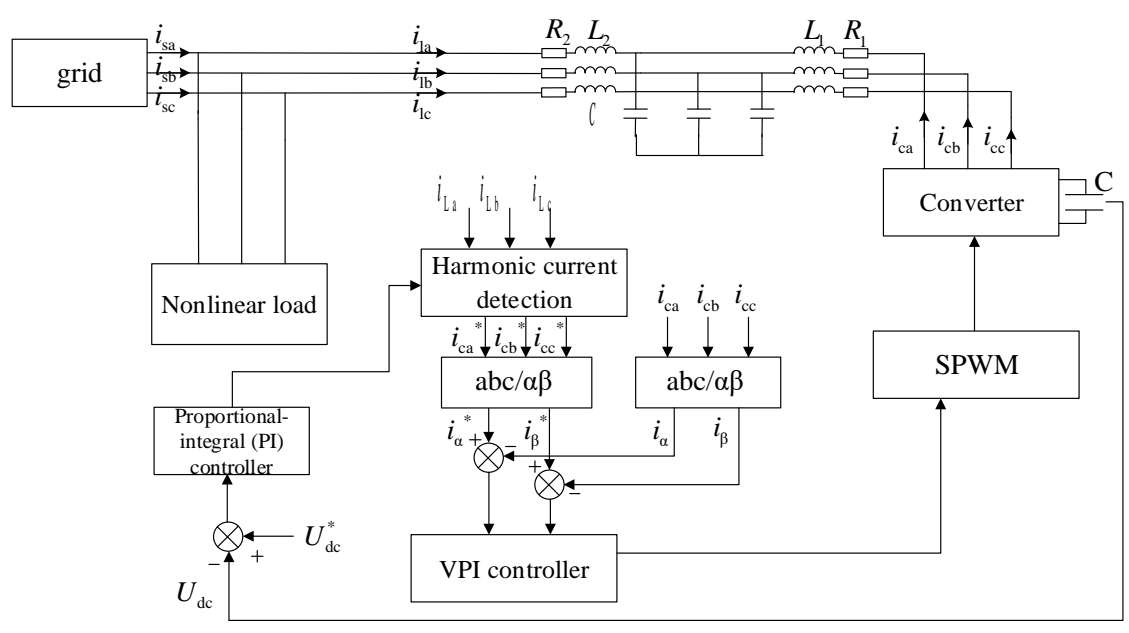

Figure 3. The principle of VPI current control under the $\alpha-\beta$ stationary coordinate system 
The transfer function of the VPI controller can be described as:

$$
G_{V P I}(s)=\frac{K_{p h} s^{2}}{s^{2}+\left(h \omega_{e}\right)^{2}}+\frac{K_{i h} s}{s^{2}+\left(h \omega_{e}\right)^{2}}
$$

The next step is to examine the time-domain response of the VPI controller. Let $M \sin \left(h \omega_{e} t+\alpha\right)$ be the alternative current (AC) input signal with the frequency of $h \omega_{e}$. The time-domain response of the AC signal after passing through the first-order term of the VPI controller can be expressed as:

$$
f_{2}=\frac{K_{i} \cdot M}{2} \cdot\left(\frac{\sin \alpha}{h \omega_{e}} \cdot \sin h \omega_{e} t+t \sin \left(h \omega_{e} t+\alpha\right)\right)
$$

The above time-domain response can be converted into (24) through the Laplace transform (23):

$$
\begin{gathered}
L\left[\frac{d f(t)}{d t}\right]=s F(s) \\
f_{1}=\frac{K_{p}}{2} M \sin \left(h \omega_{e} t+\alpha\right)+\frac{K_{p}}{2} M t h \omega_{e} \cos \left(h \omega_{e} t+\alpha\right)
\end{gathered}
$$

Hence, the time-domain response of the AC signal $M$ $\sin \left(h \omega_{e} t+\alpha\right)$ after passing through the VPI controller can be obtained by adding up $f_{1}$ and $f_{2}$ :

$$
\begin{aligned}
f_{1}+f_{2}= & \frac{K_{p}}{2} M \sin \left(h \omega_{e} t+\alpha\right)+\frac{K_{p}}{2} M t h \omega_{e} \cos \left(h \omega_{e} t+\alpha\right)+ \\
& \frac{K_{i} \cdot M}{2} \cdot\left(\frac{\sin \alpha}{h \omega_{e}} \cdot \sin h \omega_{e} t+t \sin \left(h \omega_{e} t+\alpha\right)\right)
\end{aligned}
$$

With the elapse of time $\mathrm{t}$, any $\mathrm{t}$-containing parts in the product term become much larger than those without t. Hence, the first and third terms in (25) are negligible. Then, formula (25) can be rewritten as:

$$
\begin{aligned}
f_{1}+f_{2}= & \frac{K_{p}}{2} M t h \omega_{e} \cos \left(h \omega_{e} t+\alpha\right)+ \\
& \frac{K_{i}}{2} M t \sin \left(h \omega_{e} t+\alpha\right)
\end{aligned}
$$

According to formula (26), after the AC signal passes through the VPI controller, the integral of the amplitude of the original signal and that of the signal that leads the phase of the original signal by $90^{\circ}$ can be obtained relative to time $t$. If the VPI controller is applied to the APF, the angular frequency $h \omega_{e}$ of harmonic current will increase with the order of the harmonic current to be compensated for. In this case, the first term in formula (26) is the dominant term. Then, the domain response can be described as:

$$
f \approx \frac{K_{p}}{2} M t h \omega_{e} \cos \left(h \omega_{e} t+\alpha+90^{\circ}\right)
$$

It can be seen that the VPI controller can complete the amplitude integration of the signal that leads the phase of the original signal by $90^{\circ}$ under the $\alpha-\beta$ stationary coordinate system. Hence, the VPI controller can regulate the harmonic current of any order under the $\alpha-\beta$ stationary coordinate system with no static error.

To enhance the precision of VPI current control, the proportional term $\mathrm{K}_{\mathrm{p}}$ was added to create a proportional-VPI controller. The transfer function of the new controller can be expressed as:

$$
G_{V P I}(s)=K_{p}+\frac{K_{p h} s^{2}+K_{i h} s}{s^{2}+\left(h \omega_{e}\right)^{2}}
$$

As shown in formula (28), the VPI current control compensates for the harmonic current of each order by implementing $\alpha-\beta$ transform with angular frequency $\omega_{\mathrm{e}}$ of the fundamental wave, and superimposing the transfer functions of the harmonic current controllers. Figure 4 presents the block diagram of the proposed VPI current control under the $\alpha-\beta$ stationary coordinate system.

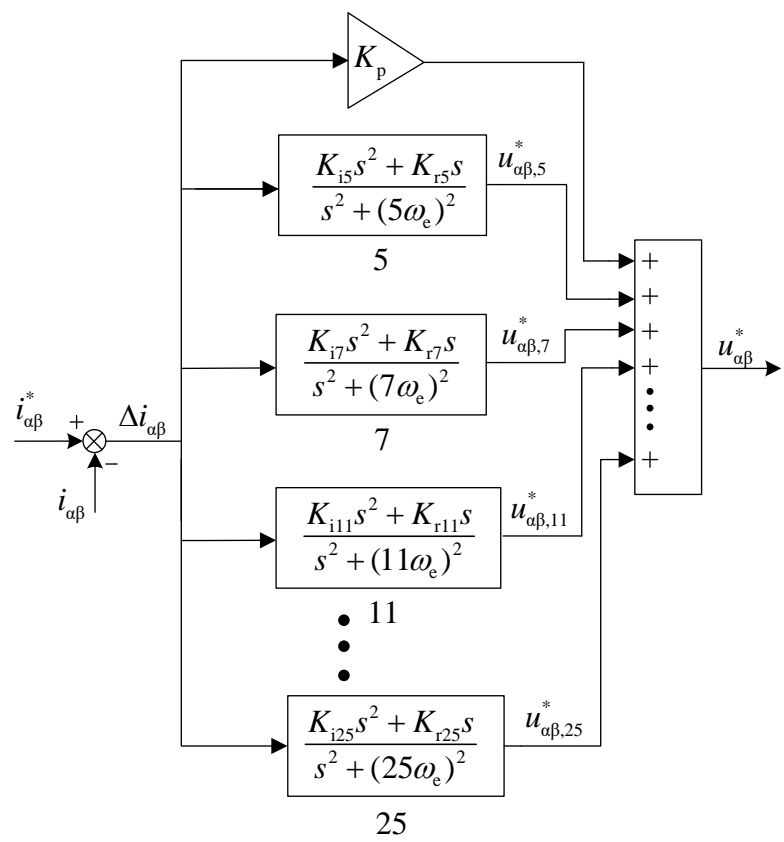

Figure 4. The block diagram of the proposed VPI current control under the $\alpha-\beta$ stationary coordinate system

\section{FEATURES OF VPI CONTROLLER UNDER A-B STATIONARY COORDINATE SYSTEM}

The above analysis shows that, under the $\alpha-\beta$ stationary coordinate system, the VPI strategy has a second-order term in the numerator, which is not included in the PR strategy. Due to the second-order term, the time-domain response of the VPI controller is the integral of the signal that leads the phase of the original signal by $90^{\circ}$. The phase advance offsets the $90^{\circ}$ phase lag in closed-loop frequency response in the current loop of the LCL filter, and maintains the amplitude-frequency at $0 \mathrm{~dB}$ at the resonance point, providing a guarantee of the precision of current control.

First, the authors compared the open-loop amplitudefrequencies in the current loop of the VPI controller and the PR controller under the $\alpha-\beta$ stationary coordinate system, when the transfer functions of the VPI controller and the PR controller are $G_{V P I}(s)=1+\left(s^{2}+100 s\right) /\left(s^{2}+\left(h \omega_{e}\right)^{2}\right) \quad$ and 
$G_{P R}(s)=1+100 s /\left(s^{2}+\left(h \omega_{e}\right)^{2}\right)$, respectively.

As shown in Figure 5, under the $\alpha-\beta$ stationary coordinate system, the response of the VPI controller had a phase advance, without any $-90^{\circ}$ jump at the resonance point. If the VPI controller is added to the LCL-APF, there will not be any $-180^{\circ}$ phase jump at the resonance point in terms of open-loop amplitude-frequency, which ensures the stability of the control system. The phase advance of the VPI controller under the $\alpha$ $\beta$ stationary coordinate system pushes up the phase of the open-loop transfer function in current loop of the APF, making up for the $90^{\circ}$ phase lag caused by the LCL filter. The phase margin at the resonance frequency will be $90^{\circ}$ greater than that of the PR controller under the $\alpha-\beta$ stationary coordinate system, expanding the stability margin of the APF open-loop control of current.

Next, the authors compared the closed-loop amplitudefrequencies in the current loop of the VPI controller and the PR controller under the $\alpha-\beta$ stationary coordinate system, when the transfer functions of the VPI controller and the PR controller are still $G_{V P I}(s)=1+\left(s^{2}+100 s\right) /\left(s^{2}+\left(h \omega_{e}\right)^{2}\right)$ and $G_{P R}(s)=1+100 s /\left(s^{2}+\left(h \omega_{e}\right)^{2}\right)$, respectively. As shown in Figure 6 , under the $\alpha-\beta$ stationary coordinate system, the VPI controller had no amplitude response peak near the resonance frequency, and maintained the amplitude gain of $0 \mathrm{~dB}$ at the harmonic current frequency for the n-th order of the harmonic current to be compensated for by the APF. Under the said system, the VPI achieved a phase response of $0^{\circ}$ at the resonance point, such as the current command obtains the passband characteristic for harmonic current at each specified order. By contrast, the PR controller was unstable at the resonance frequency under the same system, owing to phase change, and faced abnormal amplitude response peak near the resonance frequency. The comparison shows the VPI controllers overcame the defects of the PR controller under the $\alpha-\beta$ stationary coordinate system, enhancing the control precision of harmonic current.

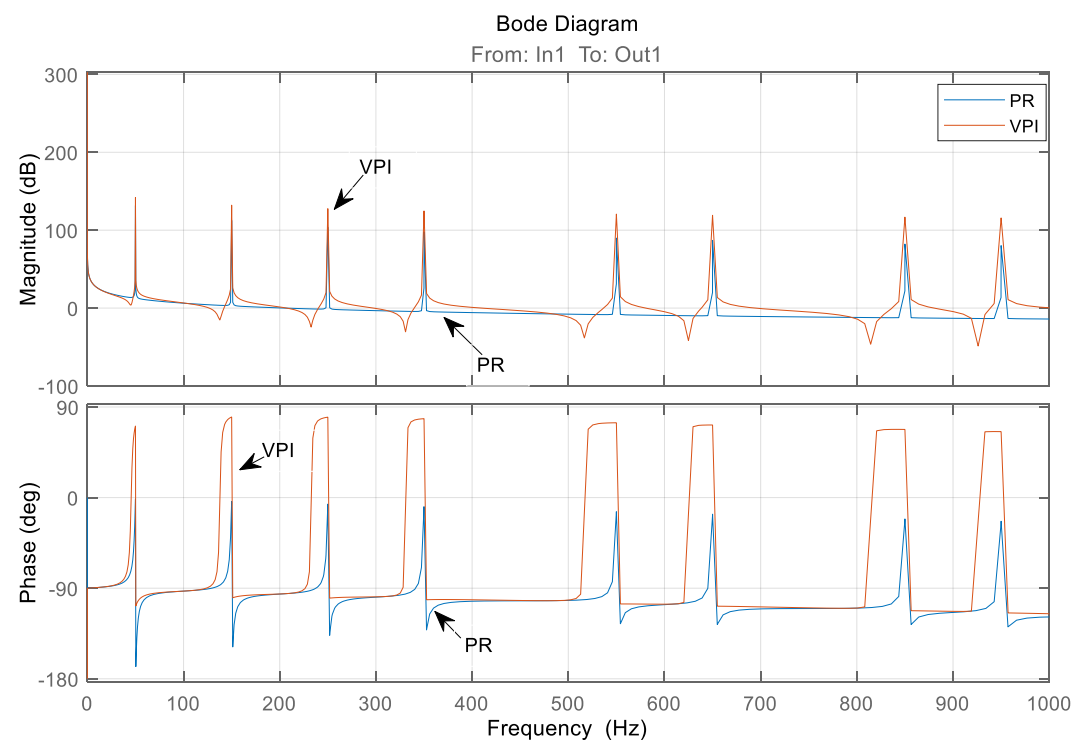

Figure 5. The Bode diagrams of PR and VPI controllers for open-loop current control

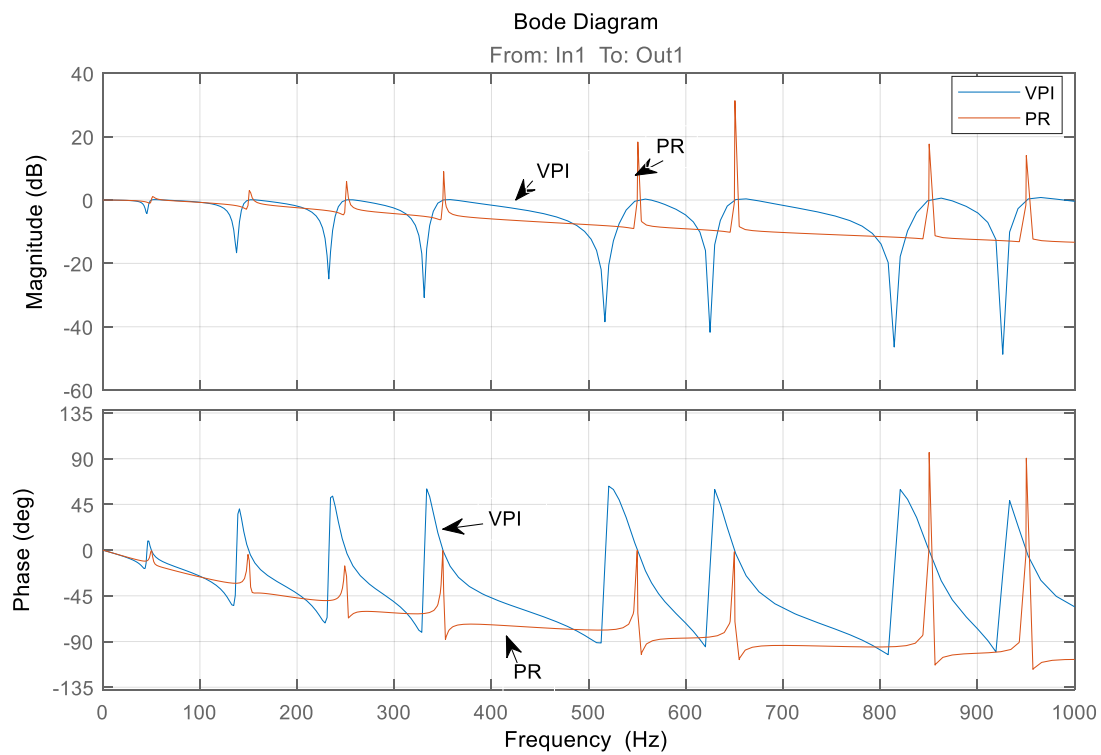

Figure 6. The Bode diagrams of PR and VPI controllers for closed-loop current control 
In summary, the proposed VPI current control strategy under the $\alpha-\beta$ stationary coordinate system is suitable for the LCL-APF, and outperforms the PR controller under the same system. While both controllers can realize error-free control of AC signals, the VPI controller, with a phase advance under the said system, can make up for the phase lag of the LCL filter, and control the closed-loop frequency response at the ideal level of $0^{\circ}$, thereby improving the precision of current control.

\section{EXPERIMENTAL VERIFICATION}

The effectiveness of the proposed VPI current control strategy under the $\alpha-\beta$ stationary coordinate system was verified through experiments on a self-designed platform for LCL-APFs. The parameters of the platform, elements and filter are listed in Tables 1 and 2.

With the typical LCL filter at the interface of the porotype, the PR strategy and VPI strategy were separately adopted to control the current, under the $\alpha-\beta$ stationary coordinate system. The order of the harmonic current to be compensated for was set to $5,7,11,13,17$ and 19 in turn.

Figures 7-9 show the waveforms and spectra of the original grid-side three-phase current, those of the grid-side threephase current compensated for by the LCL-APF with PR strategy, and those of the grid-side three-phase current compensated for by the LCL-APF with the VPI strategy,

respectively. Table 3 provides the total harmonic distortions (THDs) of the original and compensated grid-side three-phase currents.

As shown in Figure 8, Figure 9 and Table 3, the VPI strategy compensated the current of the LCL-APF more precisely than the PR strategy under the $\alpha-\beta$ stationary coordinate system.

Table 1. The parameters of the LCL-APF experimental platform

\begin{tabular}{cc}
\hline Name & Value \\
\hline System line voltage & $380 \mathrm{~V}$ \\
DC-side voltage & $740 \mathrm{~V}$ \\
Control strategy & VPI \\
AC-side voltage & $2,000 \mu \mathrm{F}$ \\
Switching frequency & $10 \mathrm{kHz}$ \\
Modulation strategy & SPWM \\
Converter & Neutral point-clamped (NPC) converter \\
Filter & LCL \\
\hline
\end{tabular}

Table 2. The parameters of the LCL filter

\begin{tabular}{cc}
\hline Parameter sign [unit] & Value \\
\hline$L_{1}[\mathrm{mH}]$ & 0.3 \\
$L_{2}[\mathrm{mH}]$ & 0.086 \\
$C_{f}[\mathrm{uF}]$ & 20 \\
$R_{d}[\Omega]$ & 1 \\
\hline
\end{tabular}

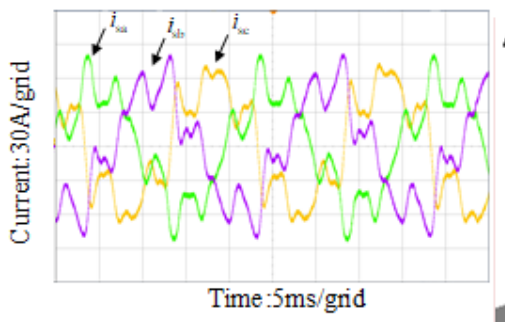

(a) Waveforms

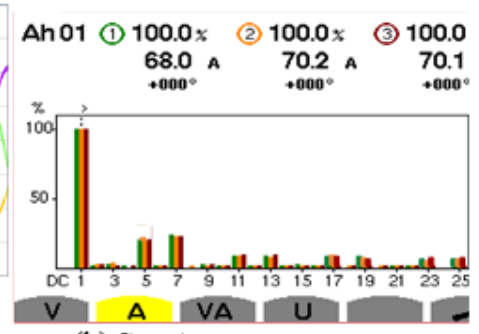

(b) Spectra

Figure 7. The original three-phase current

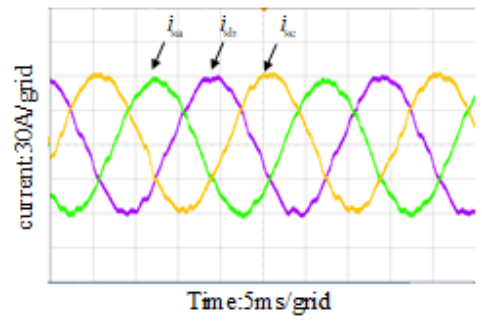

(a) Waveforms

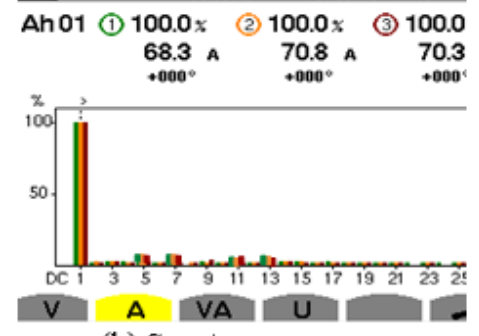

(b) Spectra

Figure 8. The three-phase current compensated by the PR strategy

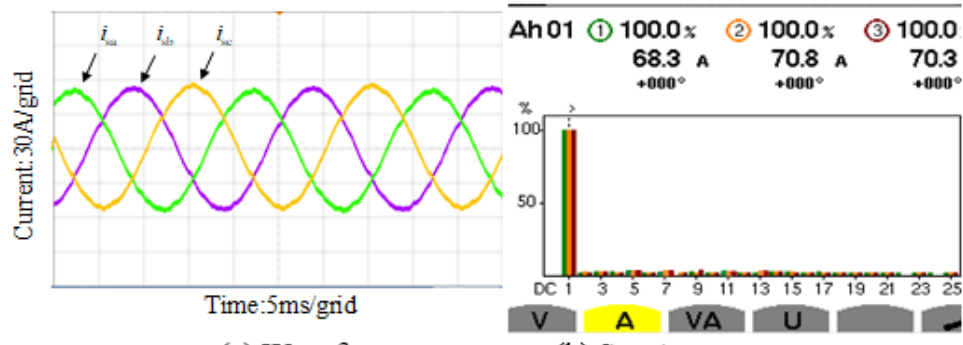

(a) Waveforms

(b) Spectra

Figure 9. The three-phase current compensated by the VPI strategy 
Table 3. The THDs of the original and compensated grid-side three-phase currents

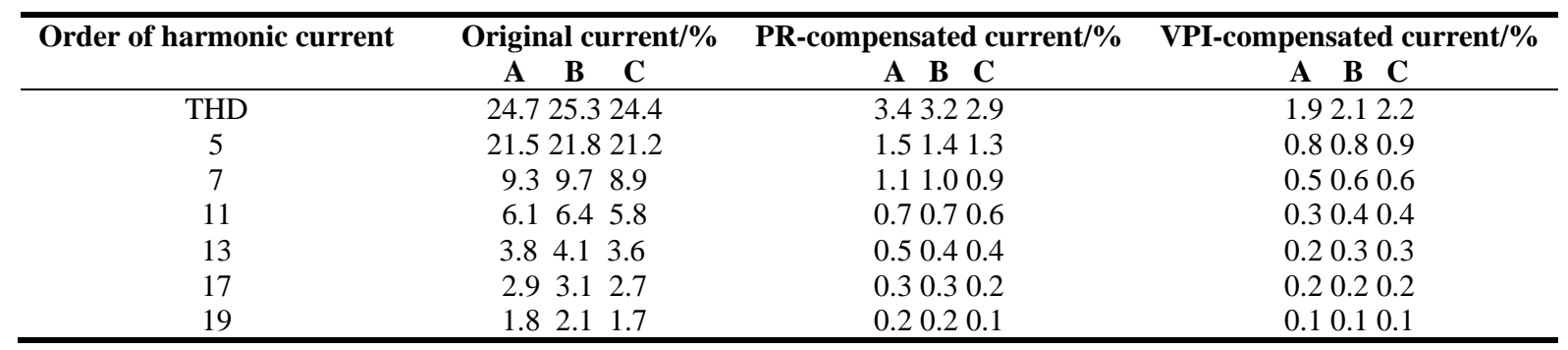

\section{CONCLUSIONS}

The traditional PR current control strategy cannot offset the decline of compensation precision induced by the phase lag of the LCL-APF. To solve the problem, this paper puts forward the VPI current control strategy under the $\alpha-\beta$ stationary coordinate system. The proposed strategy was found to outperform the PR strategy in compensation precision under the said system, through theoretical analysis and contrastive experiments.

\section{ACKNOWLEDGMENT}

This work is supported by Yancheng Institute of Technology (KJC2014009) and National Natural Science Foundation of China (11604287).

\section{REFERENCES}

[1] Tuyen, N.D., Fujita, G., Muhtazaruddin, M.N.B. (2016). Notch adaptive filter solution under unbalanced and/or distorted PCC voltage for 3-phase 3-wire shunt active power filter. Electrical Engineering, 98: 321-332. https://doi.org/10.1007/s00202-016-0362-9

[2] Benaissa, A., Rabhi, B., Benkhoris, M.F., Zellouma L. (2017). An investigation on combined operation of fivelevel shunt active power filter with PEM fuel cell. Electrical Engineering, 99: 649-663. https://doi.org/10.1007/s00202-016-0394-1

[3] Peng, T., Zhao, S., Dan, H.B., Yu, H.X. (2017). Opencircuit fault diagnosis and fault tolerance for shunt active power filter. Journal of Central South University, 24: 2582-2595. https://doi.org/10.1007/s11771-017-3672-9

[4] Pinkal, J.P., Patel, R.M., Patel, V. (2016). Implementation of FFT algorithm using DSP TMS320F28335 for shunt active power filter. Journal of The Institution of Engineers (India): Series B, 98(3): 321-327. https://doi.org/10.1007/s40031-016-0258-0

[5] Shankar, V.K.A., Kumar, N.S. (2017). Implementation of shunt active filter for harmonic compensation in a 3 phase 3 wire distribution network. Energy Procedia, 117: 172-179. https://doi.org/10.1016/j.egypro.2017.05.120

[6] Nos, O.V., Brovanov, S.V., Dybko, M.A. (2017). Development of active filtering algorithms for higher harmonics in electrical power circuits. Optoelectronics, Instrumentation and Data Processing, 52: 557-562. https://doi.org/10.3103/S8756699016060054

[7] Qian, P., Ma, X.D., Liu, G.H., Chen, Z.L. (2017). Reducing neutral-point voltage fluctuation in NPC three- level active power filters. Electrical Engineering, 100: 721-732. https://doi.org/10.1007/s00202-017-0538-y

[8] Saidi, S., Abbassi, R., Chebbi, S. (2016). Quality improvement of shunt active power filter with direct instantaneous power estimator based on Virtual Flux. International Journal of Control, Automation and Systems, $\quad 14$ https://doi.org/10.1007/s12555-014-0264-4

[9] Rao, M.U.M., Rosalina, K.M. (2019). Improvement of transient stability in microgrids using RSFCL with series active power filter. SN Applied Sciences, 1: 1633. https://doi.org/10.1007/s42452-019-1673-z

[10] Singh, Y., Hussain, I., Singh, B., Mishra, S. (2018). Single-phase single-stage grid tied solar PV system with active power filtering using power balance theory. Journal of The Institution of Engineers (India): Series B, 99: 301-311. https://doi.org/10.1007/s40031-018-0326-8

[11] Büyük, M., Tan, A., Tümay, M., Bayındır, K.Ç. (2016). Topologies, generalized designs, passive and active damping methods of switching ripple filters for voltage source inverter: A comprehensive review. Renewable and Sustainable Energy Reviews, 62: 46-69. https://doi.org/10.1016/j.rser.2016.04.006

[12] Büyük, M., Tan, A., Tümay, M. (2018) Improved adaptive notch filter-based active damping method for shunt active power filter with LCL-filte. Electrical Engineering, 100: 2037-2049 https://doi.org/10.1007/s00202-018-0685-9

[13] Sedo, J., Kascak, S. (2017). Design of output LCL filter and control of single-phase inverter for grid-connected system. Electrical Engineering, 99: 1217-1232. https://doi.org/10.1007/s00202-017-0617-0

[14] Abdul Rahman, N.F., Mohd Radzi, M.A., Che Soh, A., Mariun, N., Abd Rahim, N. (2017) Significant insights into the operation of DC-link voltage control of a shunt active power filter using different control algorithms: A comparative study. Turkish Journal of Electrical Engineering \& Computer Sciences, 25(3): 2033-2043. https://doi.org/10.3906/elk-1504-17

[15] Kouadria, M.A., Allaoui, T., Denai, M. (2016). A hybrid fuzzy sliding-mode control for a three-phase shunt active power filter. Energy Systems, 8: 297-308. https://doi.org/10.1007/s12667-016-0198-4

[16] Krama, A., Zellouma, L., Benaissa, A., Rabhi, B., Bouzidi, M., Benkhoris, M.F. (2018). Design and experimental investigation of predictive direct power control of three-phase shunt active filter with space vector modulation using anti-windup PI controller optimized by PSO. Arabian Journal for Science and Engineering, 44: 6741-6755. https://doi.org/10.1007/s13369-018-3611-6 
[17] Fang, Y.M., Fei, J.T., Cao, D. (2019). Adaptive fuzzyneural fractional-order current control of active power filter with finite-time sliding controller. International Journal of Fuzzy Systems, 21(5): 1533-1543 https://doi.org/10.1007/s40815-019-00648-4

[18] Ullah, I., Ashraf, M. (2019). Sliding mode control for performance improvement of shunt active power filter. SN Applied Sciences, 1: 531 https://doi.org/10.1007/s42452-019-0554-9

[19] Mahela, O.P., Shaik, A.G. (2016). Topological aspects of power quality improvement techniques. A comprehensive overview. Renewable and Sustainable Energy Reviews, 58: 1129-1142. https://doi.org/10.1016/j.rser.2015.12.251

[20] Benaissa, A., Rabhi, B., Benkhoris, M.F., Zellouma, L. (2016). An investigation on combined operation of fivelevel shunt active power filter with PEM fuel cell. Electrical Engineering, 99: 649-663. https://doi.org/10.1007/s00202-016-0394-1

[21] Zhou, J.H., Zhang, R., Zhang, X.W., Chen, Y.A. (2018). Improved APF specified frequency current control strategy based on stationary coordinate. Electric Drive, 2018(11): 11-20. https://doi.org/10.19457/j.1001- 2095.dqcd18331

[22] Chihab, A.A., Ouadi, H., Giri, F., Majdoub, K.E. (2015). Adaptive backstepping control of three-phase four-wire shunt active power filters for energy quality improvement. Journal of Control, Automation and Electrical Systems, 27: 144-156. https://doi.org/10.1007/s40313-015-0221-3

[23] Fereidouni, A., Masoum, M.A.S. (2016). Adaptive space-vector hysteresis-based control with constant switching-frequency for three-level shunt active power filters. Intelligent Industrial Systems, 2: 319-334. https://doi.org/10.1007/s40903-016-0064-7

[24] Zhan, C.J., Qin, Q.H., Han, Y.D., Wang, Z.H., Chen, J. (1999). Study on mathematical model and system simulation of the three-level PWM reversible rectifier. Proceedings of the Chinese Society for Electrical Engineering, $19((7)$ : 45-48. https://doi.org/10.3321/j.issn:0258-8013.1999.07.012

[25] Lascu, C., Asiminoaei, L., Boldea, I., Blaabjerg, F. (2007). High performance current controller for selective harmonic compensation in active power filters. IEEE Transactions on Power Electronics, 22(5): 1826-1835. https://doi.org/10.1109/TPEL.2007.904060 